\title{
Low Back Pain Functional Disability in Athletes; Conceptualization and Initial Development of a Questionnaire
}

\author{
Elham Zamani ${ }^{1}$; Ramin Kordi $^{1, *}$; Ruhollah Nourian ${ }^{1,2}$; Negin Noorian ${ }^{1}$; Amir Hossein Memari \\ ${ }^{1} ;$ Mohammad Shariati ${ }^{3}$ \\ ${ }^{1}$ Sports Medicine Research Center, Tehran University of Medical Sciences, Tehran, IR Iran \\ ${ }_{2}^{2}$ Noorafshar Rehabilitation and Sports Medicine Hospital, Tehran, IR Iran \\ ${ }^{3}$ Department of Community Medicine, School of Medicine, Tehran University of Medical Sciences, Tehran, IR Iran \\ ${ }^{*}$ Corresponding author: Ramin Kordi, Sports Medicine Research Center, Tehran University of Medical Sciences, Tehran, IR Iran. Tel: +98-2188630228, Fax: +98-2188003539, E-mail: \\ ramin_kordi@Tums.ac.ir
}

Received: January 30, 2014; Revised: March 15, 2014; Accepted: April 14, 2014

\begin{abstract}
Background: Low Back Pain (LBP) is one of the most prevalent causes of disability not only in the general population but also in athletes. Despite a large number of self-reported back specific disability questionnaires, there is no specific, well documented, outcome measure for athletes suffering from back pain.

Objectives: This study aimed to identify the main descriptive themes representing functional disability in athletes due to LBP.

Patients and Methods: We conducted a qualitative study using in-depth interviews to characterize the experiences of athletes with LBP. Twenty athletes with LBP were recruited and the main descriptive elements of their LBP related disability were extracted. Then a preliminary questionnaire using these themes was proposed.

Results: The main disability indicators were pain intensity; stretching exercises, strengthening exercises, sport specific skills, back range of motion (ROM), sitting, walking, sleep patterns, self-care, and recreational activities, fear of pain and avoidance behavior, and changes in sexual activity.

Conclusions: The findings of this study suggest that apart from non-sports items, some sport related items should be included in the assessment of LBP disability levels in athletes. Our results have also been organized as a preliminary LBP disability questionnaire for athletes.
\end{abstract}

Keywords:Low Back Pain; Athlete; Questionnaire Design; Disability

\section{Background}

about $80 \%$ of individuals experience at least one episode of back pain during their life span (1). Among athletes, this rate varies between $1 \%$ and $30 \%$ depending upon the training program and techniques practiced (2-4). These injuries are observed more often among wrestlers, soccer players, weight lifters, and gymnasts (4-8). Among competitive athletes LBP is one of the most common causes of missed play as well as life-long disability $(4,9)$. Assessment of disability is one of the most important components of health care service. Currently, self-reported disability measures are the most common way to evaluate patients with back pain (10). A variety of back specific indices have been developed to assess functional status in the LBP population (11-15). The most popular are the Roland-Morris Disability Questionnaire (RMDQ) (14) and the Oswestry Low Back Pain Disability Index (ODI) (15). However, these scales were designed to evaluate back pain in the general population with low physical and functional activity output $(12,16,17)$. These tools might have some limitation to evaluate the physical demands, deficits, and temporary disabilities specific to athletes and their specific exercises and activity levels (3, 18). In addition, the expectations of athletes in regards to their functional status and therapeutic outcomes differ greatly from those of the general population (18).

\section{Objectives}

Recently, the Micheli Functional Scale (MFS) was developed to evaluate LBP in young athletes (18). However, this study has focused exclusively on three physical activities. Therefore, it is limited in evaluating the impact of back pain on various components of physical activity and sport in addition to daily living activities, social and sport related evaluation of LBP disability in athletes. The aim of this study was to identify the main descriptive themes that are present with functional disability in athletes with back pain. These themes allow us to develop a specific questionnaire for assessment of athletes with LBP. 


\section{Patients and Methods}

\subsection{Design}

In this qualitative study, we used the content analysis

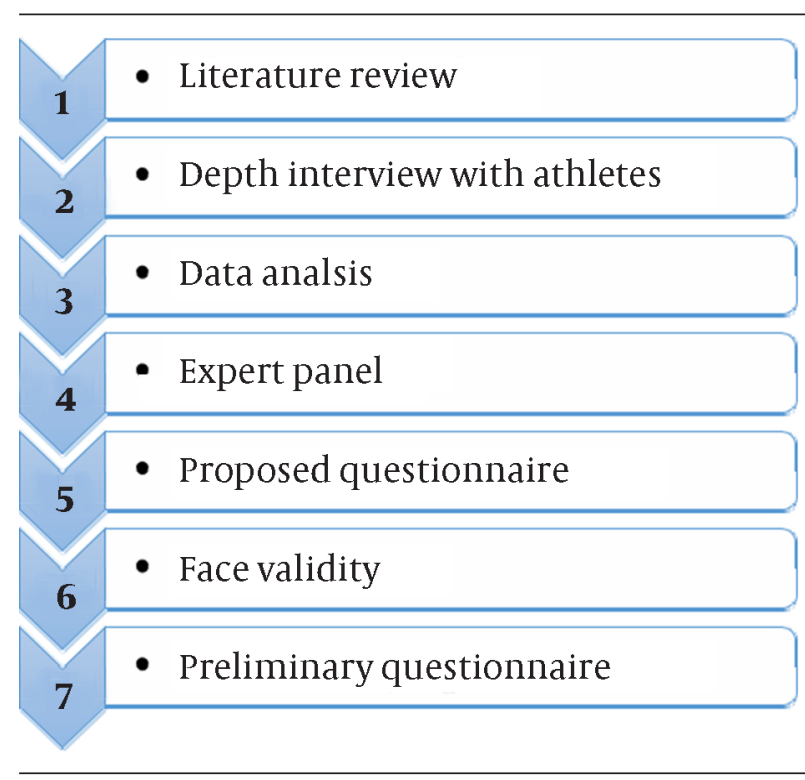

Figure 1. Study Process Flow Chart

method to conceptualize the cardinal themes that affect the activities of athletes with $\operatorname{LBP}(19,20)$. In particular, we conducted in-depth interviews with participants to identify functional deficits caused by LBP. In our study, disability was defined according to the International Classification of Functioning, Disability, and Health (ICF), a classification system of health and health-related descriptors as follow: "Disability is an umbrella term, covering impairments, activity limitations, and participation restrictions. An impairment is a problem in body function or structure; an activity limitation is a difficulty encountered by an individual in executing a task or action; while a participation restriction is a problem experienced by an individual in involvement in life situations" (21). The progression of study is shown as a flow chart in Figure 1.

\subsection{Participants}

Twenty athletes with LBP were selected using criterion purposive sampling. We continued sampling until theoretical saturation was achieved. The inclusion criteria were as follows: age between 18-35 years, normally engaging in sport activities at least three times per week, and having back pain history for at least six weeks. The exclusion criteria were: any history of oncologic problems, constitutional symptoms (fever, chills, unexpected weight loss), persistent night pain or pain during rest, history of back injury or non-sport trauma to the spine, history of recent infection or an immune compromised state, urinary or fecal incontinence due to sphincter dys- function, progressive neurological deficits, prolonged use of corticosteroid drugs, osteoporosis or neurological impairment in the lower extremities (22). Exclusion criteria were obtained from each participating patient by inperson interview and check marked forms. If there was a report of recent non-sport trauma by patient, he or she was to be excluded from study; however, any participants in our study did not state such a report. Our sample consisted of patients from the Sports Medicine Federation of the Islamic Republic of Iran and the clinic of Sport Medicine Research Center in Tehran Iran, between January 2012 and April 2012. Informed consent was obtained from all the participants in the study.

\subsection{Data Collection}

To obtain insight into the experiences of physically active people with LBP, an in-depth interview was conducted with each participant. The main domains for interview were determined by extensive literature review. The adjustable interview guide (available in Appendix 2 ) was used so that the interviewer could investigate patients' statement further if needed. Initially, we did 2 interviews as a pilot, the results of which were included in the final result. The principal investigator did all interviews. The participants were encouraged to discuss their LBP induced disability and any changes in daily living or sport specific activities that they thought were relevant to the back pain. We collected all data 6 weeks after symptoms began to ensure sufficient time to experience the back pain effects while athletes were still experiencing symptoms of back pain. Interviews took between 30 and 90 minutes. Each interview was Audio recorded and transcribed carefully while omitting any personal information. The main descriptive themes required produce a questionnaire, were obtained through analysis of the interviews. Based on these themes, we prepared a preliminary questionnaire. To phrase the proposed answers we used quotes from the interviews. In each section, our effort was to establish understandable, univocal, simple and short statements. A panel consisting of four sports medicine specialists; that were experts in the field of back pain, a qualitative research methodologist, and a psychiatrist validated the content of the questionnaire. The Content Validity Index (CVI) was used to estimate the validity of the items (23). For this purpose, a panel of experts is asked to rate the relevance of each individual item using a four points ordinal scale based on the Davis instrument (24); 1 = not relevant, 2 = somewhat relevant, 3 = quite relevant, $4=$ highly relevant. Then, for each item, the CVI index was calculate. The final draft of the preliminary questionnaire included twelve themes developed from the interviews as well as input from the expert panel. The questionnaire was then employed to assess face validity of the questionnaire by three athletes with back pain ( 2 males and one female). All three athletes agreed strongly with face validity of this questionnaire, only a 
Zamani E et al.

\begin{tabular}{|c|c|c|c|c|c|}
\hline Gender & Age, $Y$ & $\begin{array}{c}\text { Competitive or } \\
\text { Recreational }\end{array}$ & Activity & $\begin{array}{c}\text { Symptom Dura- } \\
\text { tion, } Y\end{array}$ & Diagnosis \\
\hline M & 35 & Competitive & Futsal & 3 & NSP \\
\hline M & 19 & Competitive & Cycling & 4 & NSP \\
\hline M & 30 & Competitive & Cycling & 4 & DH \\
\hline M & 22 & Competitive & Judo & 1 & NSP \\
\hline M & 35 & Competitive & Parkour & 3 & NSP \\
\hline M & 28 & Competitive & Diving & 2 & NSP \\
\hline M & 30 & Competitive & Judo & 1 & NSP \\
\hline M & 23 & Competitive & Basketball & 5 & NSP \\
\hline M & 21 & Competitive & Basketball & 0.5 & NSP \\
\hline M & 26 & Competitive & Volleyball & 4 & NSP \\
\hline M & 27 & Competitive & Basketball & 2 & NSP \\
\hline M & 34 & Recreational & Basketball, Swimming & 2 & DH \\
\hline $\mathbf{M}$ & 28 & Recreational & Endurance Running, Judo & 3 & NSP \\
\hline M & 34 & Recreational & Football & 18 & NSP \\
\hline $\mathbf{M}$ & 30 & Recreational & Climbing & 4 & NSP \\
\hline $\mathbf{F}$ & 24 & Recreational & Tennis & 0.5 & NSP \\
\hline $\mathbf{F}$ & 25 & Recreational & Track and Field & 1 & NSP \\
\hline $\mathbf{F}$ & 27 & Competitive & Handball & 2 & SIJ \\
\hline $\mathbf{F}$ & 25 & Competitive & Handball & 3 & NSP \\
\hline $\mathbf{F}$ & 26 & Competitive & Basketball & 8 & SIJ \\
\hline
\end{tabular}

${ }^{\mathrm{a}}$ M: male; F: female; NSP: nonspecific LBP; DH: disc herniation.

little wording was needed in opinion of participants. Finally, these comments were applied in the questionnaire.

\subsection{Analysis}

A thematic, descriptive approach was used to analyze the interviews. After transcription the interviewer was immersed in the data by listening to the recordings several times as well as re-reading the notes and transcripts to obtain insight into the subject's state (familiarization). The fundamental issues and concepts were extracted from the respondents' viewpoints, recurrent statements, and experiences. Then, all the data were indexed, accordingly. This index allowed us to categorize the effects of LBP into different categories. Notation was added to the interview notes and the transcripts. Next, the data were reconstructed based on the indexes and a chart for every theme was generated. Lastly, the charts were used to evaluate the concepts and highlight any correlations between the themes $(25,26)$.

\section{Results}

Twenty participants including 15 males and 5 females (mean age $=27.4 \mathrm{y}$; SD \pm 4.6 ) years (range: 19-35) were enrolled in this study. The demographic characteristics of participants are in Table 1. Our sample consisted of 14 competitive and 6 recreational athletes that practiced futsal, cycling, judo, parkour, diving, basketball, track and field, volleyball, soccer, climbing, tennis, and handball. The duration of their LBP symptoms varied from six weeks to 18 years (mean 3.5 year; $S D \pm 3.8$ ). Based on the interviews, we extracted 13 descriptive themes: pain intensity, stretching exercises, strength training, technical skills, back ROM, sitting, walking, sleep patterns, emotional reaction, self-care, recreational activities, fear of pain and avoidance behavior, and lastly, changes in sexual activity. After review, only 12 of the themes were used in the questionnaire (see discussion). Specific details regarding the indices are included below.

\subsection{Stretching Exercises}

Several athletes mentioned changes in their ability to conduct stretching exercises as a concern. Phrases such as being perfect despite suffering pain, restrictions in ROM and repetitions, and quitting some of the painful stretches were common among participants. Some examples of the Athletes' Quotes are as Follows: "I try to stretch completely, though I feel pain. I'd prefer to suffer pain rather than compromising my form in basic exercises." (23 years old basketball player) "As I bend over while stretching, some kind of progressive pain gets started in my back. The worst part is returning to 
the straight position. Such that due to pain, I do them [stretching exercises] fast and incomplete" (34 years old football player I've talked to my doctor and he told me not to aggravate my back with painful movements. So, I gave up some of the stretches" (25 years old female handball player) Moreover, the most difficult stretching movement as indicated by the interviews was hamstring stretching.

\subsection{Strengthening Exercises}

Limitations in performing resistance exercises were another common complaint among participants. The main changes and adaptations in these activities were: perform completely despite the pain, performing selective strengthening exercise to deal with back pain, and reducing intensity of the exercises. Some quotes regarding these points were: Strengthening exercises are really hard. I have to do crunches, sit-ups, and many others two times per week to strengthen my abdominal and back muscles. This is the worst section in my training session and is so painful that makes me lie down on the floor at the end of the session. However, despite the awful pain I never withdraw; instead, I keep doing my exercises to strengthen my back muscles" (35 years old soccer player) "I've tried to lift lighter weights and increase my repetitions, instead. This [compensation] comes from my own experience and may not be very scientific." (23 years old basketball player) Furthermore the most difficult exercises reported by the athletes were: power clean, squats, lunges, leg press, calf rises, and upright training with barbells.

\subsection{Sport Specific Skills (Technical Skills)}

The participants were asked about the effect of LBP on their ability to perform sport specific or technical skills. Participants reported a variety of limitations in regards to their technical skills. To describe the limitations, several codes were generated: to perfection, despite the pain, not performing well due to pain or fear of injury, restricting the skills performed under the pain threshold, stopping as soon as pain starts, and complete cessation. "Before feeling pain in my back, I was an excellent player. But now, I think it is not rational to keep playing with such a back pain; therefore, I've tried to do each activity under the pain threshold and have dropped jumping or standing on my tip toes from my training plan" (23 years old basketball player) Moreover, different codes for onset of pain during activity was identified include: pain at the beginning of exercise, pain during the whole game, pain reduction after the warm up, and delayed onset pain after exercise.

\subsection{Back ROM/Change of Direction}

One of the greatest concerns among several athletes was limitation in lumbar ROM and changing direction. Common experiences were: limitations in sudden change of direction, turning or twisting, and forward bending. ".there is some jumping, sprinting, and direction changes in every single play. Changing direction suddenly is like a shock to my back and I can't do it. It is a dramatic failure.” (26 years old basketball player) “.As a goalkeeper, sometimes to block an attempted shot, I have to bend forward or backward and twist. It is really painful. Twisting is a big problem I can't handle turning or twisting movements as I was doing before." (34 years old football player)

\subsection{Sitting}

The athletes explained that prolonged sitting, sitting on a hard seat or soft couch, and sitting on armless chairs might exacerbate their pain.

\subsection{Walking}

Fast walking, prolonged walking, walking up or down a hill, and climbing the stairs all possibly aggravated the back pain.

\subsection{Sleep}

Some of the athletes noted that their sleep patterns and quality had not been affected by back pain. However, many others described limitation using these descriptors: pain in specific sleep positions such as on the side or prone, pain during changing sleep positions, rolling over in bed, or sudden movements, and morning pain.

\subsection{Emotional Reactions}

The athletes were requested to also explain their emotional reaction to their injury and how they have been influenced by LBP. Most of them discussed being upset or having a bad emotional reaction, or worrying about their future sport life. Some of the quotes are: ".during my tennis practice, I feel down because as a professional player I can't accomplish what I used to. There is a bad feeling about my abilities and the fact that there is no way to do heavier practices" (24 years old tennis player) "As an injured athlete you'll get nervous and become upset since others can play but you can't. I'm always worried about what will happen if I can't play anymore. It is not the depression but a kind of sadness." (35 years old Parkour player) Other common emotional reaction states described by the participants were: anger, depression, desperation, and anxiety.

\subsection{Fear of Pain or (re) Injury}

During the in-depth interviews, the athletes repetitively described these experiences about pain and injury: 1 . "Fear of experiencing pain" in which they tended to avoid some activities that might increase their pain. ".after recovery, when you want to start your practice again, you are always worried about the pain. It's really a great concern. During the game you can't have your optimal performance either." (26 years old female volleyball player) 
2. "Fear of (re)injury" was explained by some athletes as an excessive fear of physical activity, this was the result of their feeling about susceptibility to severe injury (reinjury). “. during the match, jumps are my great fears. I can't jump as before any more. Whenever I want to jump I think about death" (21 years old basketball player) ".The cause of my failure is that I constantly think about my pain and tell myself this move putting pressure on my hamstring and will hurt it." (25 years old female runner) Nevertheless, some athletes continue their physical activity regardless of their LBP. One told us that: ".I has nothing to do with the fear. Thinking about injury leads to the injury. We shouldn't be afraid of the height or pain or others." (35 years old parkour player)

\subsection{Sexual Life}

Pain after sexual activity, fear of harmful impact on the back, reduction in frequency, and complete withdrawal were major concerns identified in relation to changes in sexual activity after LBP. These effects seem to increase the athletes' tension and anxiety. ". This item is very important. I could not have sex when my back pain was severe. Now, although the pain is not too annoying, it [sexual activity] has been very limited because I'm afraid of the pain." (30 years old track and field athlete) ". One of our [athletes] biggest problems with LBP is sexual disturbances. You may avoid sex because it hurts too much but then, you have to struggle with a growing distress and anxiety because the relationship with your partner and the sense of trust may be strained." (30 years old cyclist)

\subsection{Self-Care (Dressing, Using Bathroom, Bathing)}

The participants believed the problems in the self-care category were generally not of great importance. They felt that using a few simple modifications, these activities could be performed without change in quality. The participants were asked about the effect of taking bath on their back pain but no considerable problems were mentioned. The main problem noted in regards to dressing was: "difficulty in putting on the trousers, shoes, and socks". However, there were concerns about using the toilet, but these appear to be due to the local "Iranian or squat toilets" “.Squat toilets are really harmful for my back. I can't' stand the pain. But when I try western toilets, it is okay. So I avoid the Iranian ones." (21 years old basketball player)

\subsection{Recreational Activities}

Due to the diversity in our cohort, we saw differences in the impact of the LBP on recreational activities between the elite athletes and recreational athletes. Many of the elite athletes mentioned practicing their professional skills or other activities with a physical nature as a favorite leisure activity. Other participants noted traveling, shopping, hanging out with friends, and resting and relaxation as their leisure activities. Accordingly, based on the type of recreational activity, the magnitude of the
LBP effects on that varied. Based on interviews, range of changes in leisure activities were from unaffected to withdrawal from the favorite activity. Some of the descriptions were as follows: My favorite leisure activity was skiing. But, I gave it up about one year ago. Since then, I have tried to go hiking instead. Most of my friends still are skiing and it's really hard for me to accept the fact that they can, but I can't. It is not just difficult, it is terrible." (35 years old parkour player) My hobby was bowling. I used to go and play a lot, but ever since I felt this pain [LBP], I gave up [bowling] and became merely a fan." (21 years old basketball player)

\section{Discussion}

Among the original thirteen themes (pain, stretching exercises, strengthening exercises, technical skills, sitting, walking, sleeping, emotional reaction, back ROM, fear avoidance behavior, recreational activities, sex life, and self-care), the topic of "emotional reaction" was eliminated from the final draft because the experts believed that emotions such as anxiety, depression, desperation, and anger, could not be adequately assessed in one single question and that this aspect may be better evaluated using specific questionnaires $(11,14,15)$. The remaining twelve themes were sorted into three main axes: sport related issues, health/life quality, and daily living activities. A preliminary draft of the developed questionnaire for athletes with back pain was organized around these axes (Appendix 1). Issues related to daily living activities (self-care, sitting, walking, sleeping) have been addressed in general back pain questionnaires and are included in most back pain disability measures including the RMDQ (14) and ODI (15). According to our study it seems that the experience of athletes regarding limitations in daily living activities are as same as the general population, except in regards to their recreational activities and hobbies which may be unique to athletes. In line with our study, Bergner et al. used a "recreation and pastimes" item in the final version of their Sickness Impact Profile (SIP) questionnaire (27). In contrast, during the development of the RMDQ, statements related to hobbies and shopping were included in the pilot, but due to lack of interest among several patients they were excluded from the final version of questionnaire (14). This discrepancy may be the result of the levels of activity and higher physical demand of athletes. Indeed, most athletes prefer hobbies that are physically demanding, and any limitation in these activities is important to evaluate in terms of LBP induced disability. Sport related issues (stretching exercises, resistance exercises, and technical skills, back ROM, and changing direction) were a primary concern for athletes. The RMQ (14) and ODI (28) questionnaires that evaluate disability caused by LBP in the general population, do not measure disability in the context of high-demanding activities such as sports. Indeed, the authors of the Waddell Disability Index (WDI) believe that "limitations in sports activities was discounted as representing a completely 
different level of disability" (11). Furthermore, some complex tasks such as sport related activities were excluded from the Quebec back pain disability index because the authors felt these activities depended upon socioeconomic status, occupation, and patient lifestyle. Hence, sport related issues have been commonly overlooked using these questionnaires (12). To our knowledge, limitation in performing stretching exercises, resistance exercises and technical skills are not included in any back pain disability questionnaires. Restrictions in hamstring stretching exercises are frequently reported in LBP patients (29-31). The relationship between LBP and asymmetrical movements of the torso (e.g. side bending and twisting) has been evaluated previously (32-34). In our study, restrictions in back ROM or direction changes were mainly reported in turning and twisting movements of the lumbar spine. Turning, twisting, and rotational movements are the basis for other complex tasks. Limitations in these basic movements may have a great impact on many physical activities and those of daily living $(35,36)$. Fear of pain and avoidance behavior are critical in predicting chronic disability in daily living activities, occupation, and the outcome of rehabilitation in LBP patients $(9,37,38)$. The belief that physical activity will cause pain and promote re-injury (kinesiophobia) is a part of the fear-avoidance model (39-41). Avoidance is a maladaptive behavior that may exacerbate fear, reduce body fitness, and may prolong LBP disability $(11,42)$. On the one hand, "confronting" the physical activities can be an adaptive response which leads to a reduction in fear as well as recovery. The attitude of LBP patients toward their fear can be assessed by the Fear Avoidance Behavior Questionnaire (FABQ) thus this concept is not included in many LBP measures $(11,12,14$, 28). In our study, this concept arose during the interviews when athletes emphasized the critical impact of such behaviors on their disability. Thus, we included this theme in our questionnaire to attain a more accurate and reliable assessment of LBP disability in athletes. Sexual activity questions were originally included in the LBP Outcome Score (LBPOS) (42), WDI (11), and ODI (43);but in some versions of ODI sex related items were omitted (43). The fact that in many cultures questions about sexual activity are not acceptable appears to be the primary reason for elimination. Furthermore, in certain studies including those using teenagers with spondylolisthesis (44), as well as with patients having several metastases, sex-related questions were eliminated $(45,46)$. During the development of the Quebec back pain disability scale, sexual activity questions were the most frequently omitted items which also indicates the low social acceptance. Consequently, this item is generally assumed inappropriate when dealing with the general population suffering from LBP (12). Surprisingly, based on our interviews, impaired sexual activity was cited as a major concern from the athletes' point of view. This could be due to the age range of our participants. In contrast to previous LBP studies that recruited middle aged or older patients $(11,12,14,28,42)$. Therefore, questions addressing sex life were preserved in our questionnaire.

\subsection{Limitations}

This qualitative study used patient interviews as the main source of data. Consequently, some possible personal barriers between the interviewee and interviewer might have negatively affected the explicitness and sincerity of the outcome. Matching of the gender of the interviewee and interviewer in future studies can reduce this probability. Findings may also be influenced by athletes' cultures, age, gender and sport type and level, so it should be considered in future studies to determine its generalizability to a variety of athletes with back pain. Recall bias is also likely to impact data of this study because some participants were in rehabilitation course or in off-season. In this qualitative study, we identified the main limitations that athletes with LBP experience in their daily lives, as well as those related to their sport-specific activities. According to our findings, LBP induced disability in athletes primarily affected their ability to participate in sport related activities. Current LBP disability questionnaires only measure daily activities that impede their ability to accurately measure disability in an athlete with LBP. Therefore, we suggest that sport related activities be included in outcomes assessments of back pain disability among athletes. In this study, we attempted to improve our understanding of disability in athletes with LBP and identified the main limitations to develop a questionnaire (Athlete Back Pain Disability Questionnaire). Complementary studies need to be done with a broad spectrum of athletes to validate this questionnaire.

\section{Acknowledgements}

This study was part of a graduate dissertation supported by Tehran University of Medical Sciences. The authors would like to thank the athletes who participated in the study.

\section{Appendix}

Appendix 1. Athlete Back Pain Disability Questionnaire (A preliminary draft).

For your doctor to understand how your back pain is affecting you, please read each question carefully and select the statement which best applies to you in each section.

1. Pain

- I have no pain.

- I have mild pain.

- I have moderate pain.

- I have severe pain.

2. Stretching exercises

- I can perform any stretching exercise without any back pain.

- I can perform any stretching exercises but some are painful. 
- Because of back pain, I can no longer perform some stretching exercises.

- Because of back pain, I cannot perform any stretching exercises at all.

3. Strengthening/weight training exercises

- I perform all strength/resistance exercises without pain.

- I perform some exercises in a modified way to reduce or avoid pain.

- There are specific strength/resistance exercises I can't perform due to back pain.

- I have completely stopped strength/resistance exercises because of pain.

4. Sport specific skills (technical skills)

- I perform all drills without any pain or restriction.

- I perform team drills, but I have some pain.

- I can't perform some of my team's drills (or workouts) because of pain.

- I can't perform any sport specific exercises; I have to be out of action due to pain.

5. Rotational back movements/changing direction

- I have no problem rotating my back or changing direction.

- I can rotate my back and change direction but I experience some pain.

- I am restricted in rotating my back and/or changing direction due to pain.

- I cannot perform rotational back movements or change direction because of pain.

6. Sitting

- I can sit on any chair (surface) for as long as required.

- I can sit as long as required but I experience some pain.

- The amount of time I can sit at one time has been reduced.

- I can only sit for a short time before there is too much pain.

7. Walking

- I can walk on level or sloped surfaces and climb stairs without any pain.

- I can only walk on level surfaces without pain.

- The duration or speed that I can walk has been affected because of pain.

- My walking ability is severely restricted because of the pain.

8. Sleep

- I have no pain or restrictions while sleeping.

- I can sleep without pain if I position myself in a certain way.

- I sleep less hours than before because of the pain.

- My sleep has been totally disrupted.

9. Self-care (putting on socks and shoes, going to the toilet)

- I can perform all self-care activities without pain.

- I have pain during these activities but I can do them.
- I experience quite a bit of pain and cannot perform all self-care activities independently.

- I cannot perform these activities myself because of pain.

10. Fear of pain or (re)injury

- I have no fear of pain while performing sports activities/exercises.

- I perform my training despite the fear of pain.

- Fear of pain prevents me from performing some activities/movements.

- Fear of pain has made me stop training or participating in activities.

11. Recreational activities

- I perform my leisure activities without any pain.

- Despite some limitations, I do most of my leisure activities.

- I can only participate in a fraction of my favorite activities.

- My leisure activities and hobbies have been put aside due to pain.

12. Sexual Activity

- I do not experience any back pain or limitations during sexual activity.

- I have maintained my sexual activity but I do experience some back pain.

- I have had to reduce sexual activity due to pain.

- I completely refrain from sexual activity because of the back pain.

How to calculate your score:

First choice: no pain/restrictions $=0$ points

Second choice: no restrictions some pain $=1$ point

Third choice: some restrictions to limit pain $=2$ points

Fourth choice; restricted due to pain $=3$ points

Sum up the points, thus the minimum possible score will be zero and the maximum possible score will be 36.Total score is divided by 36 then multiplied by 100 .

Appendix 2. Interview guide format

Purpose of the study

To identify the main descriptive themes that represent functional disability in athletes due to low back pain

\section{Questions}

Tell me about yourself.

Please describe how back pain affects your daily life activities.

Please describe how back pain affects performing selfcare.

Please describe how back pain affects your sport activities. Please describe how back pain affects your warm up.

Please describe how back pain affects your ability to do stretching exercise.

Please describe how back pain affects your participation in training sessions.

Please describe how back pain affects your ability to do specific techniques and skills.

Please describe how back pain affects your hobbies and recreational activities.

Please describe how back pain affects your walking. 
Please describe how back pain affects your sitting. Please describe how back pain affects your standing. Please describe how back pain affects your running. Please describe how back pain affects your interaction with others.

Please describe how back pain affects your mood, psychosocial behavior and self-esteem.

Please describe how back pain affects your sexual life.

\section{Acknowledgments}

This study was part of a graduate dissertation supported by Tehran University of Medical Sciences. The authors would like to thank the athletes who participated in the study

\section{References}

1. Freburger JK, Holmes GM, Agans RP, Jackman AM, Darter JD, Wallace AS, et al. The rising prevalence of chronic low back pain. Archives of internal medicine. 2009;169(3):251.

2. Heck JF, Sparano JM. A classification system for the assessment of lumbar pain in athletes. Journal of athletic training. 2000;35(2):204.

3. Vela LI, Haladay DE, Denegar C. Clinical assessment of low-backpain treatment outcomes in athletes. Journal of sport rehabilitation. 2011;20(1):74.

4. Bono CM. Low-back pain in athletes. The Journal of Bone and Joint Surgery (American). 2004;86(2):382-96.

5. Granhed H, Morelli B. Low back pain among retired wrestlers and heavyweight lifters. The American journal of sports medicine. 1988;16(5):530-3.

6. Lundin O, Hellström M, Nilsson I, Swärd L. Back pain and radiological changes in the thoraco - lumbar spine of athletes. A long - term follow - up. Scandinavian journal of medicine $\mathcal{E}$ science in sports. 2001;11(2):103-9.

7. Swärd L, Hellstrom M, Jacobsson B, Pëterson L. Back pain and radiologic changes in the thoraco-lumbar spine of athletes. Spine. 1990;15(2):124

8. HUTCHINSON MR. Low back pain in elite rhythmic gymnasts. Medicine \& Science in Sports \& Exercise. 1999;31(11):1686.

9. Waddell G, Newton M, Henderson I, Somerville D, Main CJ. A Fear-Avoidance Beliefs Questionnaire (FABQ) and the role of fear-avoidance beliefs in chronic low back pain and disability. Pain. 1993;52(2):157-68.

10. Mousavi SJ, Parnianpour M, Mehdian H, Montazeri A, Mobini B. The Oswestry Disability Index, the Roland-Morris Disability Questionnaire, and the Quebec Back Pain Disability Scale: translation and validation studies of the Iranian versions. Spine (Phila Pa 1976). 2006;31(14):E454-9.

11. WADDELL G, MAIN CJ. Assessment of severity in low-back disorders. Spine. 1984;9(2):204.

12. Kopec JA, Esdaile JM, Abrahamowicz M, Abenhaim L, WoodDauphinee S, Lamping DL, et al. The Quebec back pain disability scale: conceptualization and development. Journal of clinical epidemiology. 1996;49(2):151-61.

13. Million R, Hall W, Nilsen KH, Baker RD, Jayson MI. Assessment of the progress of the back-pain patient 1981 Volvo Award in Clinical Science. Spine. 1982;7(3):204.

14. Roland M, Morris R. A study of the natural history of back pain: part I: development of a reliable and sensitive measure of disability in low-back pain. Spine. 1983;8(2):141.

15. Intensity P. Modified Oswestry Low Back Pain Disability Questionnaire. Physiotherapy. 1980;66:271-3.

16. Deyo RA. Measuring the functional status of patients with low back pain. Archives of Physical Medicine and Rehabilitation. 1988;69(12):1044.

17. Kopec JA, Esdaile JM. Functional disability scales for back pain Spine. 1995;20(17):1943.

18. d'Hemecourt PA, Zurakowski D, d'Hemecourt CA, Curtis C, Ugri- now V, Deriu L, et al. Validation of a New Instrument for Evaluating Low Back Pain in the Young Athlete. Clinical Journal of Sport Medicine. 2012.

19. Elo S, Kyngas H. The qualitative content analysis process. J Adv Nurs. 2008;62(1):107-15.

20. Tong A, Sainsbury P, Craig J. Consolidated criteria for reporting qualitative research (COREQ): a 32-item checklist for interviews and focus groups. Int J Qual Health Care. 2007;19(6):349-57.

21. International classification of Functioning, Disability and Health.Geneva: world health organization; 2001.

22. Leerar PJ, Boissonnault W, Domholdt E, Roddey T. Documentation of red flags by physical therapists for patients with low back pain. J manual mani therap. 2007;15(1):42.

23. Lynn MR. Determination and quantification of content validity. Nurs Res J.1986;35(6):382-5.

24. Linda Lindsey Davis . Instrument review: Getting the most from your panel of experts. Applied Nursing Research. 1992;5(4):194-7.

25. Smith J, Firth J. Qualitative data analysis: the framework approach. Nurse researcher. 2011;18(2):52.

26. Pope C, Ziebland S, Mays N. Qualitative research in health care: Analysing qualitative data. BMJ: British Medical Journal. 2000;320(7227):114.

27. Bergner M, Bobbitt RA, Carter WB, Gilson BS. The Sickness Impact Profile: development and final revision of a health status measure. Medical care. 1981:787-805.

28. Fairbank JC, Couper J, Davies JB, O'brien JP. The Oswestry low back pain disability questionnaire. Physiotherapy. 1980;66(8):271-3.

29. Halbertsma JPK, Göeken LNH, Hof AL, Groothoff JW, Eisma WH Extensibility and stiffness of the hamstrings in patients with nonspecific low back pain. Archives of Physical Medicine and Rehabilitation. 2001;82(2):232-8.

30. Esola MA, McClure PW, Fitzgerald GK, Siegler S. Analysis of lumbar spine and hip motion during forward bending in subjects with and without a history of low back pain. Spine. 1996;21(1):71-8

31. McHUGH MP, Kremenic IJ, Fox MB, Gleim GW. The role of mechanical and neural restraints to joint range of motion during passive stretch. Medicine and science in sports and exercise. 1998;30(6):928.

32. Andersson GB. Epidemiologic aspects on low-back pain in in dustry. Spine. 1981;6(1):53.

33. Jin K, Sorock GS, Courtney T, Liang Y, Yao Z, Matz S, et al. Risk factors for work-related low back pain in the People's Republic of China. International journal of occupational and environmental health. 2000;6(1):26-33.

34. Wong TKT, Lee RYW. Effects of low back pain on the relationship between the movements of the lumbar spine and hip. Human movement science. 2004;23(1):21-34.

35. Kopec JA. Concepts of disability: The activity space model. Socia science \& medicine. 1995;40(5):649-56.

36. Nagi SZ. Disability concepts revisited: implications for prevention. Disability in America: Toward a national agenda for prevention.1991:309-27.

37. Crombez G, Vlaeyen JWS, Heuts PHTG, Lysens R. Pain-related fear is more disabling than pain itself: evidence on the role of pain-related fear in chronic back pain disability. Pain. 1999;80(1):329-39.

38. Pfingsten M, Kröner - Herwig B, Leibing E, Kronshage U, Hildebrandt J. Validation of the German version of the Fear - Avoidance Beliefs Questionnaire (FABQ). European Journal of Pain. 2000;4(3):259-66.

39. Lethem J, Slade PD, Troup JDG, Bentley G. Outline of a fearavoidance model of exaggerated pain perception-I. Behaviour research and therapy. 1983;21(4):401-8.

40. Vlaeyen JW, Kole-Snijders AM, Rotteveel AM, Ruesink R, Heuts $\mathrm{PH}$. The role of fear of movement/(re) injury in pain disability. Journal of occupational rehabilitation. 1995;5(4):235-52.

41. Vlaeyen JW, Seelen HA, Peters M, de Jong P, Aretz E, Beisiegel E, et al. Fear of movement/(re) injury and muscular reactivity in chronic low back pain patients: an experimental investigation. Pain. 1999;82(3):297-304

42. Greenough CG, Fraser RD. Assessment of outcome in patient with low-back pain. Spine. 1992;17(1):36-41. 
43. Fairbank JC, Pynsent PB. The Oswestry disability index. Spine. 2000;25(22):2940-53.

44. Poussa M, Schlenzka D, Seitsalo S, Ylikoski M, Hurri H, Österman K. Surgical treatment of severe isthmic spondylolisthesis in adolescents: reduction or fusion in situ. Spine.1993;18(7):894-901.

45. Purohit OP, Anthony C, Radstone CR, Owen J, Coleman RE. High- dose intravenous pamidronate for metastatic bone pain. British journal of cancer. 1994;70(3):554.

46. Tyrrell CT, Bruning PP, May-Levin F, Rose C, Mauriac L, Soukop M, et al. Pamidronate infusions as single-agent therapy for bone metastases: A phase II trial in patients with breast cancer. European Journal of Cancer. 1995;31(12):1976-80. 